\title{
Mavrilimumab: an evidence based review of its potential in the treatment of rheumatoid arthritis
}

This article was published in the following Dove Press journal:

Core Evidence

12 March 2014

Number of times this article has been viewed

\section{Manuela Di Franco \\ Maria Chiara Gerardi \\ Bruno Lucchino \\ Fabrizio Conti}

Reumatologia, Dipartimento di Medicina Interna e Specialità Mediche, Sapienza Università di Roma, Rome, Italy
Correspondence: Manuela Di Franco Reumatologia, Dipartimento di Medicina Interna e Specialità Mediche, Sapienza Università di Roma, Viale del Policlinico I55, 00 I6I, Rome, Italy

Tel +390649974639

Email manuela.difranco@uniromal.it
Abstract: Rheumatoid arthritis (RA) management has greatly improved with the development of biologic disease modifying antirheumatic drugs, but a proportion of patients do not improve despite the biologic drugs currently available. We need new biologic agents with novel mechanisms of action for the treatment of refractory patients. Recent evidence has shown that granulocyte-macrophage colony-stimulating factor (GM-CSF) is involved in the pathogenesis of RA. GM-CSF can exacerbate RA and elevated levels of this cytokine have been observed in synovial fluid from RA patients. Antagonism of GM-CSF can strikingly reduce established disease in mouse models of arthritis. Mavrilimumab, a human monoclonal antibody to GMCSF receptor $\alpha$, is a competitive antagonist of GM-CSF signaling. Phase I and II studies have shown good clinical response with a good safety profile in patients with mild to moderate RA, suggesting encouraging effects of mavrilimumab for the treatment of RA. This paper reviews the preclinical and clinical data evaluating the safety, tolerability, and efficacy of mavrilimumab in the treatment of RA.

Keywords: rheumatoid arthritis, GM-CSF, mavrilimumab

Clinical impact summary for mavrilimumab/rheumatoid arthritis

\begin{tabular}{|c|c|c|}
\hline $\begin{array}{l}\text { Outcome } \\
\text { measure }\end{array}$ & Evidence & Implications \\
\hline $\begin{array}{l}\text { Disease-oriented } \\
\text { evidence }\end{array}$ & $\begin{array}{l}\text { Granulocyte-macrophage colony- } \\
\text { stimulating factor (GM-CSF) } \\
\text { administration can exacerbate } \\
\text { rheumatoid arthritis (RA) and it is } \\
\text { found in the joints of patients } \\
\text { with RA } \\
\text { Antagonism of GM-CSF can } \\
\text { markedly reduce established } \\
\text { disease in mouse models of RA }\end{array}$ & \\
\hline $\begin{array}{l}\text { Patient-oriented } \\
\text { evidence }\end{array}$ & $\begin{array}{l}\text { Phase I and II trials have defined } \\
\text { well the maximal tolerated } \\
\text { doses and schedules }\end{array}$ & $\begin{array}{l}\text { Recommended doses and } \\
\text { schedules can be evaluated } \\
\text { in ongoing studies }\end{array}$ \\
\hline $\begin{array}{l}\text { Generally well } \\
\text { tolerated }\end{array}$ & $\begin{array}{l}\text { Safety and adverse event profiles } \\
\text { have been defined by Phase I } \\
\text { and II trials }\end{array}$ & $\begin{array}{l}\text { Mild or moderate adverse } \\
\text { events reported }\end{array}$ \\
\hline Good efficacy & $\begin{array}{l}\text { Good clinical response } \\
\text { in Phase II trial }\end{array}$ & \\
\hline $\begin{array}{l}\text { Economic } \\
\text { evidence }\end{array}$ & $\begin{array}{l}\text { Unknown as mavrilimumab has } \\
\text { not been approved for marketing }\end{array}$ & \\
\hline
\end{tabular}




\section{Introduction}

Rheumatoid arthritis (RA) is a systemic chronic autoimmune disease characterized by persistent and erosive inflammatory polyarthritis. It can also affect other organs, such as the lungs, cardiovascular system, skin, and eyes. RA affects approximately $1 \%$ of the world population and if not properly treated, leads to progressive destruction of joints with consequent disability, loss of function and mobility or work incapacity, and decreased quality of life and life expectancy. ${ }^{1}$ Traditional disease modifying antirheumatic drugs (DMARDs) have become the cornerstone of treatment for RA, with methotrexate (MTX) at present considered as the "gold standard" in RA therapy, in monotherapy or in combination with other drugs. However, patients with an inadequate response to treatment with traditional DMARDs or MTX may be treated with biologic agents targeting tumor necrosis factor (TNF) and interleukins (IL)-6 and -1, which play a pivotal role during pathological processes active in RA, and with biologic agents targeting T- and B-cells (eg, abatacept, rituximab). Biologic DMARDs (eg, TNF inhibitors, abatacept, rituximab, tocilizumab) have shown greater efficacy than traditional DMARDs (eg, methotrexate, sulfasalazine) in controlling joint damage. Significant improvement of physical function and quality of life has been reported, although a recent study demonstrated similar effects with triple traditional DMARDs treatment. ${ }^{2,3}$ Nonetheless, the combination of conventional and biologic DMARDs may provide an earlier resolution of the inflammatory process and may increase the response rate. The introduction of biologic agents with different immunological targets into clinical routine has been associated with a significant improvement in RA treatment, however a substantial proportion of patients do not achieve appropriate disease control and some of them interrupt treatment due to inefficacy or adverse events. ${ }^{4} \mathrm{New}$ therapeutic strategies with different mechanisms of action are mandatory in nonresponder patients or patients who experience adverse events. Recent evidence supports the role of granulocyte-macrophage colony-stimulating factor (GM$\mathrm{CSF}$ ) in the pathogenesis of RA and suggests the inhibition of its receptor as a novel therapeutic approach in RA. This paper reviews the preclinical and clinical data for mavrilimumab when used in the treatment of RA.

\section{GM-CSF}

GM-CSF, as the name suggests, is a soluble cytokine that promotes the proliferation and differentiation of granulocytes and macrophages from bone marrow precursor cells and stimulates their activation. In some cases, it regulates survival and activation of eosinophils. ${ }^{5}$ In addition, it controls numerous functions of mature tissue macrophages, such as cell adhesion, expression of pathogen recognition receptors, and proinflammatory cytokines (TNF $\alpha$, IL-12, IL-18, IL-6, monocyte chemotactic protein 1 , and macrophage colony stimulating factor), phagocytosis, and microbial killing. ${ }^{6}$ As shown below, GM-CSF aids the normal pulmonary physiology by stimulating macrophages in clearing surfactant lipids and proteins from the lung surface. ${ }^{7}$ Upon appropriate stimulation, it is secreted by different cell types including fibroblasts, endothelial cells, T-cells, macrophages, mesothelial cells, and epithelial cells. In vitro studies have shown that the proinflammatory cytokines IL- 1 and TNF- $\alpha$ induce GM-CSF secretion from fibroblasts, endothelial cells, chondrocytes, and smooth muscle cells. ${ }^{8-11}$ Lipopolysaccharide can stimulate GM-CSF formation from monocytes or macrophages, which in turn take part in the cellular response to lipopolysaccharide. ${ }^{12}$

GM-CSF binds specifically to its receptor composed of a cytokine specific $\alpha$-chain (GM-CSF receptor $\alpha$ chain $[\mathrm{GMR} \alpha])$ and $\beta$-chain, which are in common with the receptors for IL-3 and IL-5. It associates with GMR $\alpha$ with low affinity and rapid dissociation kinetics, but the formation of the $\alpha \beta$ heterodimeric complex mediates a stable interaction with high affinity and slow dissociation kinetics. The binding of GM-CSF activates the Janus kinase-signal transducers and activators of transcription-suppressor of cytokine signaling (JAK-STAT-SOCS) 3 signaling pathway. ${ }^{13}$

In a murine model, ${ }^{7}$ GM-CSF deficient mice grow up seemingly healthy and fertile up to 12 weeks of age. Although they do not show any significant hematopoietic alterations, all of them develop lung pathology. This is characterized by peribronchovascular infiltration with lymphocytes, predominantly B-cells, and intra-alveolar infiltration of phagocytic macrophages, granular eosinophilic material, and lamellar bodies, indicative of surfactant accumulation. Some mice have subclinical lung infections involving bacterial or fungal organisms. Certain histological features of lungs from GMCSF deficient mice resemble those of human alveolar proteinosis, a heterogeneous group of congenital and acquired lung disorders characterized by accumulation of surfactant protein within alveoli and often complicated by infection. These data suggest that GM-CSF may have a pivotal role in lung physiology and resistance to local infection. ${ }^{7}$

Conversely, transgenic mice for GM-CSF with elevated levels of GM-CSF in the serum, urine, peritoneal cavity, and eyes develop accumulation of macrophages in the eyes, together with retinal damage. Similar lesions are observed in the striated muscle and in the peritoneal and pleural cavities. ${ }^{14}$ A high proportion of transgenic mice die with muscle wasting at 2-4 months of age, probably due to macrophage activation as a result of the high levels of GM-CSF. ${ }^{14}$ 


\section{GM-CSF and RA}

In an animal study, GM-CSF deficient mice with collageninduced arthritis (CIA) develop a milder disease in comparison with wild type mice, suggesting that GM-CSF plays an important role in inflammatory joint disease ${ }^{15}$ However, in a murine model of CIA, neutralizing monoclonal antibodies to GM-CSF ameliorates existing disease and prevents disease progression. ${ }^{16}$ In humans, flare up of RA in patients receiving recombinant GM-CSF after chemotherapy has been observed, as well as in Felty's syndrome, after administration of GM-CSF to correct neutropenia. ${ }^{17,18}$

GM-CSF may be implicated in the pathogenesis of RA through the activation, differentiation, and survival of neutrophils and macrophages. Macrophages induce synovitis through release of cytokines, chemokines, reactive oxygen and nitrogen intermediates, proteases, and microparticles. ${ }^{19}$

Xu et al reported higher levels of GM-CSF in the synovial fluid from patients with RA in comparison to those obtained from other chronic inflammatory forms of arthritis, suggesting a local production of GM-CSF in rheumatoid synovitis. ${ }^{20}$ Accordingly, Fiehn et al described elevated concentrations of GM-CSF in the plasma of patients with RA when compared to the control group. ${ }^{21}$ The central role of GM-CSF in the pathogenesis of RA is also described in a study by Singh and colleagues. ${ }^{22}$ They reported an early macrophage infiltration in synovium in eight patients with very early RA ( $<6$ weeks duration) even prior to the development of lymphoid aggregates or increased vascularity. ${ }^{22}$ Indeed, it has been demonstrated that the number of synovial macrophages correlates significantly with radiologic erosion and changes in the number of synovial sublining macrophages during therapy with anti-rheumatic drugs, and correlates significantly with reduction of Disease Activity Score (DAS) 28, supporting a role for synovial macrophages as a sensitive biomarker of clinical response to therapy of RA. ${ }^{19,23,24}$

\section{Preclinical data}

All these findings show that GM-CSF may have a crucial role in the pathogenesis of RA, leading to the hypothesis that inhibiting GM-CSF through its receptor (GM-CSFR- $\alpha$ ) is a novel therapeutic approach. Mavrilimumab (CAM-3001) is a human monoclonal antibody IgG4 that competitively binds to GM-CSFR- $\alpha$, inhibiting GM-CSF signaling.

An in vitro study has shown that peripheral blood mononuclear cells produce TNF in a dose-dependent manner if stimulated by GM-CSF and the anti-GM-CSFR antibody, CAM-3001, inhibits IL-8, IL-6, and TNF in a dose-dependent manner. ${ }^{25}$
An in vitro study conducted in cynomolgus monkeys has demonstrated that leukocyte margination and leukocytosis induced by GM-CSF is inhibited by CAM-3001. Mavrilimumab demonstrated equipotency in GM-CSF inhibition in humans and in cynomolgus monkeys. ${ }^{25}$

\section{Clinical trials}

To date, Phase I/II studies have demonstrated a good safety profile and efficacy of mavrilimumab in patients affected by RA. In a randomized, double-blind, placebo-controlled, dose escalating Phase I study (NCT00771420), Burmester et $\mathrm{al}^{26}$ evaluated the safety, tolerability, and pharmacokinetic and pharmacodynamic profiles of mavrilimumab in 32 subjects with mild to moderate RA (DAS28 $\leq 4.8$ ) of $\geq 6$ months duration and who had received a stable dose of MTX for $\geq 3$ months. Patients were randomized to receive a single, escalating intravenous dose of mavrilimumab $(0.01,0.03$, $0.1,0.3,1.0,3.0$, and $10.0 \mathrm{mg} / \mathrm{kg}$ ) or placebo. Subjects were followed for 24 weeks after infusion. Over the 24-week study period, the most commonly reported adverse events across cohorts were nasopharyngitis, headache, diarrhea, and back pain. Mild and moderate adverse events were described with similar frequency within all treatment groups. One subject, who received the dose of $10.0 \mathrm{mg} / \mathrm{kg}$, experienced face and neck urticaria that resolved after symptomatic treatment. Lung function tests did not show any differences at baseline and at week 12. No clinical viral infections were reported and no patient experienced clinically significant laboratory abnormalities or changes in vital signs during the study. No evidence of anti-mavrilimumab antibodies was observed. Systemic clearance of mavrilimumab was similar to that of endogenous IgG at doses $>1.0 \mathrm{mg} / \mathrm{kg}$ and pharmacodynamic activity was confirmed in the 1.0 and $3.0 \mathrm{mg} / \mathrm{kg}$ groups by SOCS $3 \mathrm{mRNA}$ transcripts. As this was a Phase I study designed to evaluate the safety and tolerability profile of mavrilimumab, clinical activity was not formally determined. Even though no significant change was observed in DAS28, C-reactive protein (CRP) levels, and erythrocyte sedimentation rate (ESR), a significant reduction of CRP in patients with elevated CRP at baseline and a significant reduction of DAS28 in patients with DAS28 $>3.2$ at baseline was described. ${ }^{26}$

In a randomized, double-blind, placebo-controlled Phase II study (NCT01050998), ${ }^{27}$ the same authors tested the efficacy and safety of mavrilimumab in 233 patients with at least moderate RA (DAS28-CRP $\geq 3.2$ ) of $\geq 3$ months duration receiving stable MTX for $\geq 4$ weeks. Subjects, recruited at 53 centers across Eastern European countries, were randomized within each cohort and received either $10(n=39), 30(n=41), 50(n=39)$, or $100 \mathrm{mg}$ 
$(n=39)$ subcutaneous doses of mavrilimumab or placebo $(n=75)$ every other week for 12 weeks. The proportion of subjects achieving a reduction of DAS 28 -CRP $\geq 1.2$, the primary endpoint, was higher in treated patients (all doses combined, $\mathrm{n}=158$ ) when compared to placebo $(n=75)$ at 12 weeks $(55.7 \%$ versus $34.7 \% ; P=0.003)$. Desired responses were seen in $41 \%$ of patients on $10 \mathrm{mg}$ of mavrilimumab, in $61 \%$ of those on $30 \mathrm{mg}$, in $53.8 \%$ on $50 \mathrm{mg}$, and in $66.7 \%$ on $100 \mathrm{mg}$. Patients started to show benefits after just 2 weeks on mavrilimumab and the effects increased throughout the 12 -week treatment period. The researchers also found that levels of biomarkers associated with disease activity were lower at week 12 than at the beginning of the study, indicating that the drug was helping to suppress patients' RA. Positive effects were mainly observed at the highest dose (100 mg). In the $100 \mathrm{mg}$ dose cohort the following were observed: a higher proportion of patients with DAS28-CRP $<2.6$ compared to placebo at week $12(23.1 \%$ versus $6.7 \%, P=0.016)$, improvement in the Health Assessment Questionnaire Disability Index (HAQ-DI) score at week 12 compared to the placebo group $(-0.48$ versus $-0.25, P=0.005)$, and a greater response rate versus placebo according to the American College of Rheumatology (ACR) response criteria (ACR20: 69.2\% versus $40.0 \%, P=0.005$; ACR50: $30.8 \%$ versus $12.0 \%$, $P=0.021$; ACR70: $17.9 \%$ versus $4.0 \%, P=0.030) .{ }^{28}$ In the treated group (all doses), a larger proportion of subjects had a moderate or good European League Against Rheumatism response versus placebo (67.7 versus $50.7 \%, P=0.025)$. The mavrilimumab group showed a significant reduction in CRP and ESR versus placebo from week 2 and a significant change in swollen and tender joint count from week 4. According to the Phase I study, adverse events were mild to moderate: reduction in diffusing capacity of the lung for carbon monoxide (DLCO), mild to moderate nasopharyngitis, and upper respiratory tract infections. ${ }^{26}$ In the 30, 50, and $100 \mathrm{mg}$ cohorts, there was no difference in DLCO event rate when compared to placebo and no clinically significant or persistent changes in lung function tests performed by spirometry was observed. No significant hypersensitivity reactions, or serious or opportunistic infections, were reported. In this study, one placebo (1.3\%) subject and ten mavrilimumab $(6.3 \%$; 3 at $10 \mathrm{mg}, 4$ at $30 \mathrm{mg}, 1$ at $50 \mathrm{mg}$, and 2 at $100 \mathrm{mg}$ ) subjects developed high titer antidrug antibodies. Even if this positivity was associated with a reduced pharmacokinetic exposure, no apparent correlation was observed between antidrug antibodies and hypersensitivity or reduced clinical response ${ }^{27}$ (see Table 1). The data from the published Phase I/II studies support the potential clinical efficacy of mavrilimumab in RA.

\section{Ongoing studies}

There are three ongoing clinical trials testing mavrilimumab in RA. The first (NCT01706926) is a randomized, doubleblind, placebo-controlled, Phase IIb study to evaluate the efficacy and safety of mavrilimumab in subjects with moderate to severe RA. It includes four arms: low dose mavrilimumab + MTX, medium dose mavrilimumab + MTX, high dose mavrilimumab + MTX, and placebo group. This study is active, but not recruiting participants. ${ }^{29}$ The second trial (NCT01712399) is a nonrandomized, open label Phase II study to evaluate the long term safety and tolerability of mavrilimumab in adult subjects with RA. It is an extension study for patients who have participated in one of the qualifying development program studies with mavrilimumab and, at present, is recruiting participants. ${ }^{30}$ The third trial (NCT01715896), a randomized, double-blind, placebo-controlled Phase II study, has been designed to compare the efficacy and safety of a subcutaneous dose of mavrilimumab with a marketed treatment for RA (golimumab) in 120 adult subjects with moderate to severe active RA who have had an inadequate response to one or two anti-TNF agents. It consists of two study arms: mavrilimumab and golimumab alternating with placebo. It is active and still recruiting ${ }^{31}$ (see Table 1).

Other GM-CSF antagonists, MOR103 and KB003, have been developed. MOR103 is a fully humanized monoclonal antibody to human GM-CSF. A randomized, double-blind, placebo-controlled Phase I/II clinical trial (NCT01023256) to evaluate the safety of MOR103 in active RA has been completed. ${ }^{32} \mathrm{~KB} 003$ is a humanized monoclonal antibody targeting GM-CSF and it has been tested in RA in a randomized Phase I clinical trial (NCT00995449). ${ }^{33}$

\section{Future directions}

In the last decade, RA management has changed drastically thanks to an enhanced understanding of the pathogenesis of the disease. A number of different cellular responses are involved in the pathogenesis of RA, including activation of immune inflammatory cells and expression of various cytokines and local growth factors, as well as local angiogenesis. Macrophages, T-cells, B-cells, and neutrophils concentrate mainly in synovial tissue and produce both inflammatory and degradative mediators that break down the extracellular matrix of cartilage and bone. ${ }^{1}$ The introduction over the last decade of novel targeted therapies for RA, such as biologic DMARDs, has led to achievement of the "goal" of disease 

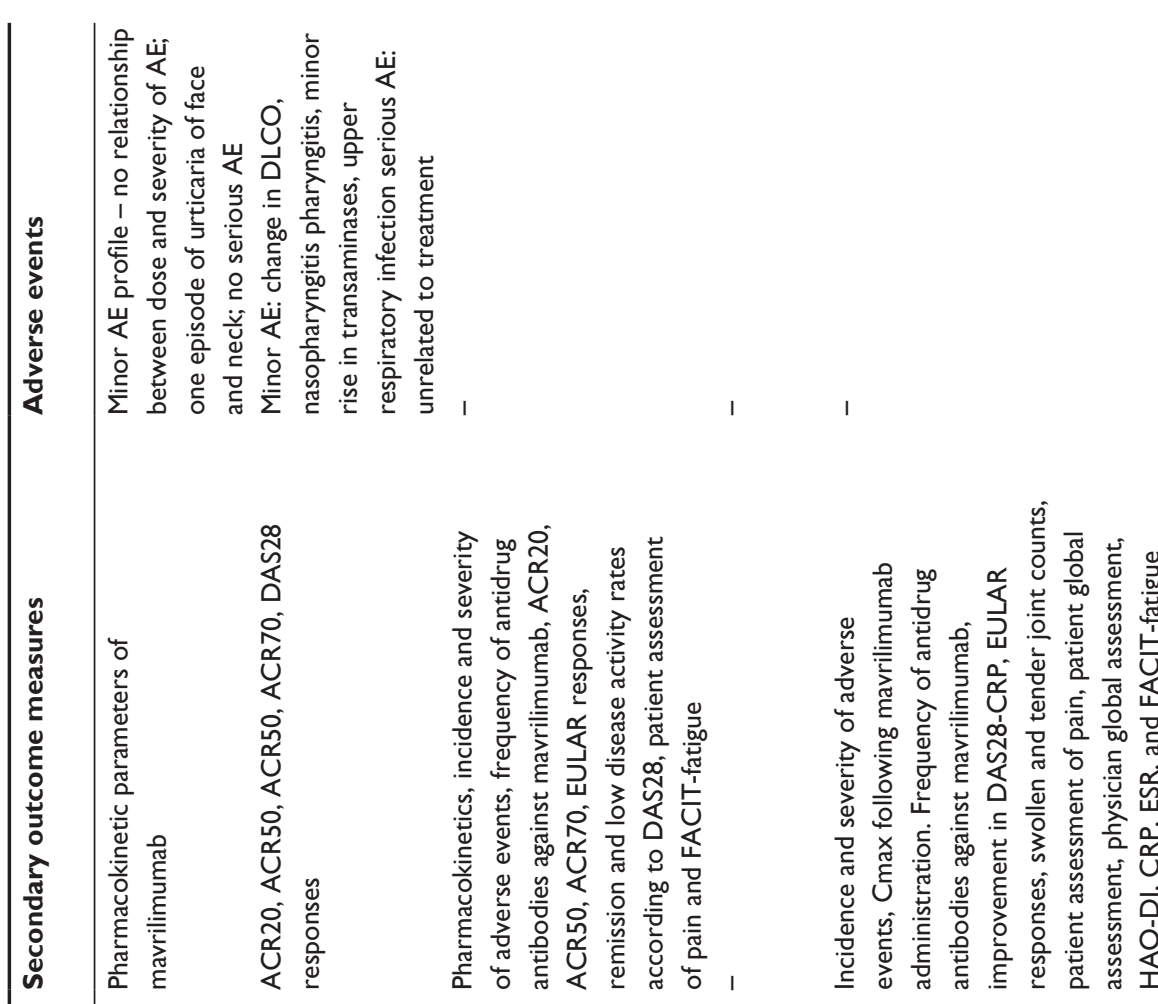

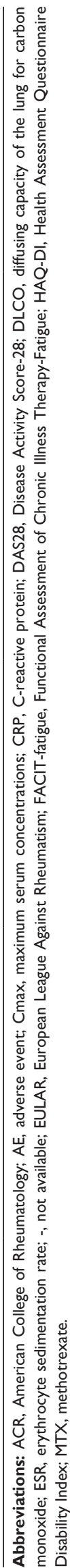
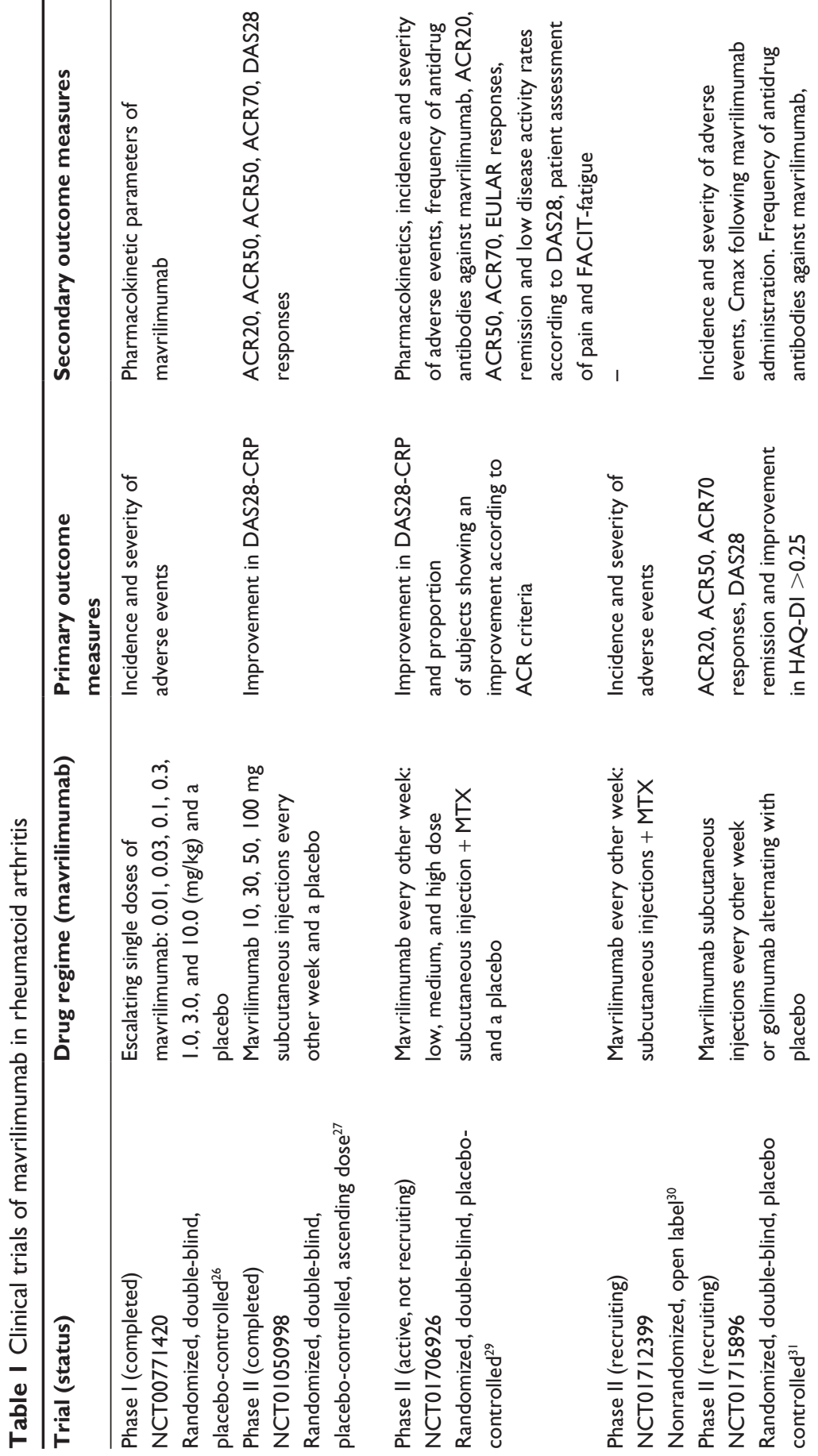

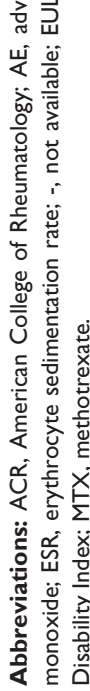


remission better than older drugs. Several biologic agents, which block cytokines other than TNF or cells involved in the pathogenesis of RA, have been developed, and at present, a vast therapeutic armamentarium is available. However, about $30 \%$ of RA patients do not respond to the first biologic agent, in most cases an inhibitor of TNF $\alpha$, and $40 \%$ discontinue these drugs within a year and 50\% within 2 years. ${ }^{434-38}$ In addition, even in patients fulfilling criteria for clinical remission, joint destruction may continue with repair of bone erosions rarely occurring, suggesting residual subclinical inflammation. ${ }^{39}$ Moreover, currently available biologic DMARDs are associated with potential adverse events, including increased risk of infections such as tuberculosis, lymphoma, and other malignancies. ${ }^{40}$

The development of additional therapeutic strategies is necessary to prevent joint damage and improve quality of life in refractory patients or subjects who experience adverse effects. Moreover, the "treat to target" strategy, a patientcentered therapy which focuses on achieving remission through tight control of the disease, increasingly requires new drugs that act in different stages of disease pathogenesis. ${ }^{41}$ Nonresponders or partial responders may have less TNFdependent disease and may benefit from subsequent treatment with a targeted therapy of a different class. Mavrilimumab is the first biologic agent that selectively blocks GM-CSF which is involved in the activation, differentiation, and survival of neutrophils and macrophages. This mechanism of action results in inhibition of what may be a central pathogenetic pathway underlying inflammation in RA.

Although the clinical studies available are limited, the data are encouraging. In the Phase I trial, ${ }^{26}$ mavrilimumab has shown good tolerability and safety. In the Phase II clinical trial, ${ }^{27}$ mavrilimumab achieved the primary endpoint (reduction of DAS28-CRP $\geq 1.2$ ) when compared with placebo at week 12 and an improvement in HAQ-DI and ACR responses was observed. This positive result was mainly driven by the higher dose $(100 \mathrm{mg})$, with clinical effects observed within the first 2 weeks of treatment. In the Phase I and II clinical studies, ${ }^{26,27}$ mild or moderate adverse events were reported. No significant lung test abnormalities were observed. Even though the Phase II study was a short term study with a small number of subjects in each treatment group, it suggests that mavrilimumab may be a novel approach for RA treatment. ${ }^{27}$

The safety of mavrilimumab needs to be evaluated in a larger number of patients who have received treatment for longer periods. At present, an ongoing trial is evaluating the long term safety of the drug. ${ }^{30}$ Trials to date have reported clinical efficacy in patients with mild to moderate disease, and a study to test the efficacy of mavrilimumab in patients with moderate to severe disease is currently underway. ${ }^{29}$ Moreover, it is important to know what the risk of infections is, and specifically, the risk of reactivation of latent mycobacterial infection, as established for other biologics, as well as the risk of malignancy during therapy with mavrilimumab. In addition, its efficacy should also be monitored using imaging techniques to evaluate effects on structural progression and head-to-head studies with other biologic agents are necessary. In the Phase II trial subjects were randomized mainly in Eastern European countries. ${ }^{27}$ Future studies should evaluate the efficacy and adverse events in a wider population.

Direct head-to-head trials and/or further appropriately powered clinical experiences (including long term safety data), along with robust pharmacoeconomic studies, are mandatory to more definitively position mavrilimumab relative to other currently available DMARDs. If the positive results observed in the available studies can be sustained and replicated in Phase III trials, it could offer another treatment option for patients.

Since RA is a lifelong disease often evolving into disability, development of new treatment strategies remains crucial. Mavrilimumab may be an additional option for patients who fail to respond to currently available traditional and biologic DMARDs or who experience serious adverse events.

\section{Disclosure}

The authors report no conflict of interest in this work

\section{References}

1. McInnes IB, Schett G. The pathogenesis of rheumatoid arthritis. N Engl J Med. 2011;365(23):2205-2219.

2. Singh JA, Furst DE, Bharat A, et al. 2012 update of the 2008 American College of Rheumatology recommendations for the use of disease-modifying antirheumatic drugs and biologic agents in the treatment of rheumatoid arthritis. Arthritis Care Res (Hoboken). 2012;64(5):625-639.

3. O'Dell JR, Mikuls TR, Taylor TH, et al; CSP 551 RACAT Investigators. Therapies for active rheumatoid arthritis after methotrexate failure. N Engl J Med. 2013;369(4):307-318.

4. Papagoras C, Voulgari PV, Drosos AA. Strategies after the failure of the first anti-tumor necrosis factor alpha agent in rheumatoid arthritis. Autoimmun Rev. 2010;9(8):574-582.

5. Hamilton JA. Colony-stimulating factors in inflammation and autoimmunity. Nat Rev Immunol. 2008;8(7):533-544.

6. Shibata Y, Berclaz PY, Chroneos ZC, Yoshida M, Whitsett JA, Trapnell BC. GM-CSF regulates alveolar macrophage differentiation and innate immunity in the lung through PU.1. Immunity. 2001;15(4):557-567.

7. Stanley E, Lieschke GJ, Grail D, et al. Granulocyte/macrophage colony-stimulating factor-deficient mice show no major perturbation of hematopoiesis but develop a characteristic pulmonary pathology. Proc Natl Acad Sci U S A. 1994;91(12):5592-5596.

8. Bagby GC Jr, Dinarello CA, Wallace P, Wagner C, Hefeneider S, McCall E. Interleukin 1 stimulates granulocyte macrophage colonystimulating activity release by vascular endothelial cells. J Clin Invest. 1986;78(5):1316-1323. 
9. Leizer T, Cebon J, Layton JE, Hamilton JA. Cytokine regulation of colony-stimulating factor production in cultured human synovial fibroblasts: I. Induction of GM-CSF and G-CSF production by interleukin-1 and tumor necrosis factor. Blood. 1990;76(10):1989-1996.

10. Campbell IK, Novak U, Cebon J, Layton JE, Hamilton JA. Human articular cartilage and chondrocytes produce hemopoietic colonystimulating factors in culture in response to IL-1. J Immunol. 1991; 147(4):1238-1246.

11. Filonzi EL, Zoellner H, Stanton H, Hamilton JA. Cytokine regulation of granulocyte-macrophage colony stimulating factor and macrophage colony-stimulating factor production in human arterial smooth muscle cells. Atherosclerosis. 1993;99(2):241-252.

12. Hamilton JA. Coordinate and noncoordinate colony stimulating factor formation by human monocytes. J Leukoc Biol. 1994;55(3):355-361.

13. Shi Y, Liu CH, Roberts AI, et al. Granulocyte-macrophage colonystimulating factor (GM-CSF) and T-cell responses: what we do and don’t know. Cell Res. 2006;16(2):126-133.

14. Lang RA, Metcalf D, Cuthbertson RA, et al. Transgenic mice expressing a hemopoietic growth factor gene (GM-CSF) develop accumulations of macrophages, blindness, and a fatal syndrome of tissue damage. Cell. 1987;51(4):675-686.

15. Campbell IK, Rich MJ, Bischof RJ, Dunn AR, Grail D, Hamilton JA. Protection from collagen-induced arthritis in granulocyte-macrophage colony-stimulating factor-deficient mice. J Immunol. 1998;161(7): 3639-3644.

16. Cook AD, Braine EL, Campbell IK, Rich MJ, Hamilton JA. Blockade of collagen-induced arthritis post-onset by antibody to granulocytemacrophage colony-stimulating factor (GM-CSF): requirement for GM-CSF in the effector phase of disease. Arthritis Res. 2001;3(5) 293-298.

17. de Vries EG, Willemse PH, Biesma B, Stern AC, Limburg PC, Vellenga E. Flare-up of rheumatoid arthritis during GM-CSF treatment after chemotherapy. Lancet. 1991;338(8765):517-518.

18. Hazenberg BP, Van Leeuwen MA, Van Rijswijk MH, Stern AC, Vellenga E. Correction of granulocytopenia in Felty's syndrome by granulocyte-macrophage colony-stimulating factor. Simultaneous induction of interleukin-6 release and flare-up of the arthritis. Blood. 1989;74(8):2769-2770.

19. Mulherin D, Fitzgerald O, Bresnihan B. Synovial tissue macrophage populations and articular damage in rheumatoid arthritis. Arthritis Rheum. 1996;39(1):115-124.

20. Xu WD, Firestein GS, Taetle R, Kaushansky K, Zvaifler NJ. Cytokines in chronic inflammatory arthritis. II. Granulocyte-macrophage colonystimulating factor in rheumatoid synovial effusions. J Clin Invest. 1989;83(3):876-882.

21. Fiehn C, Wermann M, Pezzutto A, Hüfner M, Heilig B. [Plasma GM-CSF concentrations in rheumatoid arthritis, systemic lupus erythematosus and spondyloarthropathy]. Z Rheumatol. 1992;51(3):121-126. German.

22. Singh JA, Pando JA, Tomaszewski J, Schumacher HR. Quantitative analysis of immunohistologic features of very early rheumatoid synovitis in disease modifying antirheumatic drug- and corticosteroidnaïve patients. J Rheumatol. 2004;31(7):1281-1285.

23. Bresnihan B, Gerlag DM, Rooney T, et al. Synovial macrophages as a biomarker of response to therapeutic intervention in rheumatoid arthritis: standardization and consistency across centers. J Rheumatol. 2007;34(3):620-622.

24. Bresnihan B, Pontifex E, Thurlings RM, et al. Synovial tissue sublining CD68 expression is a biomarker of therapeutic response in rheumatoid arthritis clinical trials: consistency across centers. J Rheumatol. 2009;36(8):1800-1802.

25. Nair JR, Edwards SW, Moots RJ. Mavrilimumab, a human monoclonal GM-CSF receptor- $\alpha$ antibody for the management of rheumatoid arthritis: a novel approach to therapy. Expert Opin Biol Ther. 2012;12(12): 1661-1668.
26. Burmester GR, Feist E, Sleeman MA, Wang B, White B, Magrini F. Mavrilimumab, a human monoclonal antibody targeting GM-CSF receptor- $\alpha$, in subjects with rheumatoid arthritis: a randomised, double-blind, placebo-controlled, phase I, first-in-human study. Ann Rheum Dis. 2011;70(9):1542-1549.

27. Burmester GR, Weinblatt ME, McInnes IB, et al; EARTH Study Group. Efficacy and safety of mavrilimumab in subjects with rheumatoid arthritis. Ann Rheum Dis. 2013;72(9):1445-1452.

28. Felson DT, Anderson JJ, Boers JJ et al. American College of Rheumatology preliminary definition of improvement in rheumatoid arthritis. Arthritis Rheum. 1995;38:727-735.

29. A study of mavrilimumab in subjects with moderate-to-severe rheumatoid arthritis [webpage on the Internet]. Bethesda, MD: ClinicalTrials.gov. Available from: http://clinicaltrials.gov/ct2/show/NCT01706926? term=mavrilimumab\&rank=2. Accessed October 19, 2013.

30. A long term safety study of mavrilimumab in adult subjects with rheumatoid arthritis [webpage on the Internet]. Bethesda, MD: ClinicalTrials.gov. Available from: http://clinicaltrials.gov/ct2/show/NCT01712399?term= mavrilimumab\&rank=3. Accessed October 19, 2013.

31. A study of mavrilimumab versus anti tumour necrosis factor in subjects with rheumatoid arthritis [webpage on the Internet]. Bethesda, MD: ClinicalTrials.gov. Available from: http://clinicaltrials.gov/ct2/show/NC T01715896?term=mavrilimumab\&rank=1. Accessed October 19, 2013.

32. A study of the safety and preliminary efficacy of MOR103, a human antibody to granulocyte macrophage colony-stimulating factor (GM-CSF), in patients with active rheumatoid arthritis [webpage on the Internet]. Bethesda, MD: ClinicalTrials.gov. Available from: http://clinicaltrials. gov/ct2/show/study/NCT01023256?term=MOR103\&rank=1. Accessed September 30, 2013.

33. Study of KB003 in biologics-inadequate rheumatoid arthritis [webpage on the Internet]. Bethesda, MD: ClinicalTrials.gov. Available from: http://clinicaltrials.gov/ct2/show/NCT00995449?term=kb003\&rank=2. Accessed September 30, 2013.

34. Weinblatt ME, Keystone EC, Furst DE, et al. Adalimumab, a fully human anti-tumor necrosis factor alpha monoclonal antibody, for the treatment of rheumatoid arthritis in patients taking concomitant methotrexate: the ARMADA trial. Arthritis Rheum. 2003;48(1):35-45.

35. Weinblatt ME, Kremer JM, Bankhurst AD, et al. A trial of etanercept, a recombinant tumor necrosis factor receptor: Fc fusion protein, in patients with rheumatoid arthritis receiving methotrexate. $N$ Engl J Med. 1999;340(4):253-259.

36. Keystone E, Heijde DV, Mason D Jr, et al. Certolizumab pegol plus methotrexate is significantly more effective than placebo plus methotrexate in active rheumatoid arthritis: findings of a fifty-two-week, phase III, multicenter, randomized, double-blind, placebo-controlled, parallel-group study. Arthritis Rheum. 2008;58(11):3319-3329.

37. Kremer JM, Genant HK, Moreland LW, et al. Effects of abatacept in patients with methotrexate-resistant active rheumatoid arthritis: a randomized trial. Ann Intern Med. 2006;144(12):865-876.

38. Smolen JS, Beaulieu A, Rubbert-Roth A, et al; OPTION Investigators. Effect of interleukin-6 receptor inhibition with tocilizumab in patients with rheumatoid arthritis (OPTION study): a double-blind, placebocontrolled, randomised trial. Lancet. 2008;371(9617):987-997.

39. Walsh NC, Gravallese EM. Bone remodeling in rheumatic disease: a question of balance. Immunol Rev. 2010;233(1):301-312.

40. Ruderman EM. Overview of safety of non-biologic and biologic DMARDs. Rheumatology (Oxford). 2012;51 Suppl 6:vi37-vi43.

41. Smolen JS, Aletaha D, Bijlsma JW, et al; T2T Expert Committee. Treating rheumatoid arthritis to target: recommendations of an international task force. Ann Rheum Dis. 2010;69(4):631-637. 


\section{Publish your work in this journal}

Core Evidence is an international, peer-reviewed open-access journal evaluating the evidence underlying the potential place in therapy of drugs throughout their development lifecycle from preclinical to postlaunch. The focus of each review is to evaluate the case for a new drug or class in outcome terms in specific indications and patient groups.

The manuscript management system is completely online and includes a very quick and fair peer-review system, which is all easy to use. Visit http://www.dovepress.com/testimonials.php to read real quotes from published authors.

Submit your manuscript here: http://www.dovepress.com/core-evidence-journal 